\title{
Effect of Annona Muricata Extracts on Some Biochemical Parameters in Rats Exposed to Induced Liver Tumor
}

\author{
Mohammed Ibrahim Anwer *1, Luma Abd Almunim Baker ${ }^{2}$ \\ ${ }^{1,2}$ Department of Chemistry, College of Education for Pure Sciences, University of Mosul, Mosul, Iraq \\ E-mail: ${ }^{1 *}$ mohammed.iban94@gmail.com,${ }^{2}$ lumabaker50@uomosul.edu.iq
}

(Received July 09, 2020; Accepted August 31, 2020; Available online March 01, 2021)

DOI: 10.33899/edusj.2020.127597.1088, (c) 2020, College of Education for Pure Science, University of Mosul.

This is an open access article under the CC BY 4.0 license (http://creativecommons.org/licenses/by/4.0/).

\begin{abstract}
:
This research included a study of some biochemical variables of Wister male rats with Induced liver cancer and a study of the effect of extracts of three parts of Annona muricata, including seeds, core, and leaves. The animals were divided into eight groups each group had six rats I: Control group, II treated with Thioacetamide TAA, III treated with Core extract, IV treated with Seed extract, $\mathbf{V}$ treated with Leave extract, VI treated with TAA with core extract, VII treated with TAA and Seed extract and, VIII TAA with leave extract. In this study, the measurement kit was used to measure, also Manual methods used to estimate Glutathione, Malondialdehyde, and Paraoxonase. The results showed a $\mathrm{P} \leq 0.05$ increase in the tumor-induced rats of Malondialdehyde, Alkaline phosphatase, Total bilirubin, Aspartate transaminase, Alanine-transaminase, and Alpha-fetoprotein compared to the control group, while there was a significant decrease in rats which treated with TAA of Total protein, Glutathione, and Paraoxonase compared to the control group. The results showed a significant decrease in the levels in tumor-affected animals and treated with seed extract for each Malondialdehyde, Alkaline phosphatase, Total bilirubin, Aspartate transaminase, Alanine transaminase, and Alphafetoprotein compared to the group of rats affected and treated with the core extract, and leaves, The results also showed a significant increase in the affected rats which treated with seeds extract for the level of Total protein, Glutathione, and Paraoxonase compared to the group treated with Core, leaves, this has been demonstrated by the histological sections of the liver.
\end{abstract}

Keywords: Thioacetamide, Alpha-fetoprotein, Hepatocellular Carcinoma, Annona Muricata, Malondialdehyde.

$$
\begin{aligned}
& \text { تأثير مُستخلصات نبات القشطة على بعض المتغيرات الكيموحيوية في الجرذان المصابة بأورام الكبا } \\
& \text { محمد ابراهيم أنور 1" و لمى عبد المنعم بكر2 } \\
& \text { 1 - جامعة الموصل, كلية التربية للعلوم الصرفة, قسم الكيمياء }
\end{aligned}
$$


السيطرة 2__ 3جموعة تعامل بمادة 3AA_مجوعة تعامل بمُستخلص النباتي اللب 4_مجموعة تعامل بمستخلص البذور 5_مجموعة

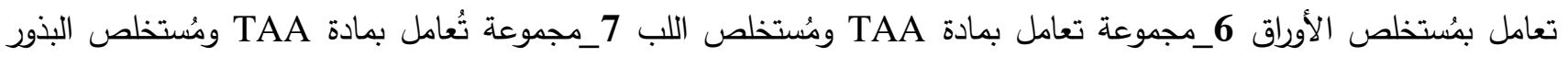
8_مAموعة تعامل بمادة TAA ومستخلص الأوراق. وقد أُستخدمت في هذه الدراسة عدة التحليل Kit ، وأيضآ طريقة التَحضَّير اليدوية لتقدير كل من الكلوتاثيون، المالونديالديهايد، والباروكسونيز، حيث التهائ أظهرت النتائج وجود إرتفاع معنوي في الجُرذان المُعاملة

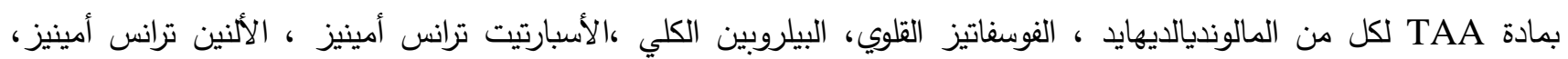

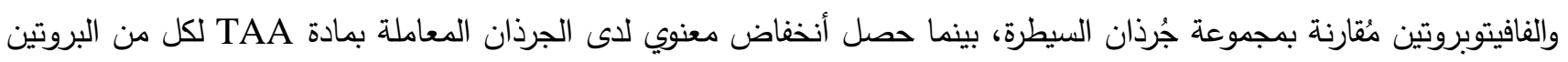

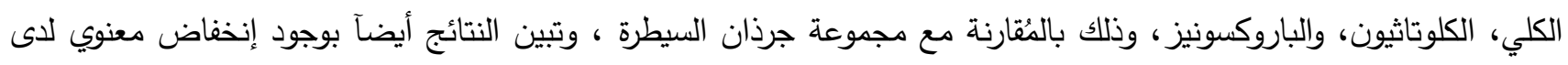

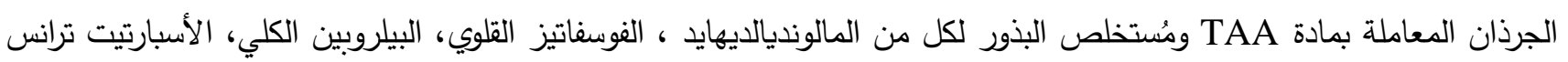

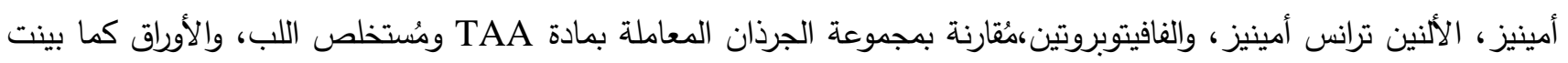

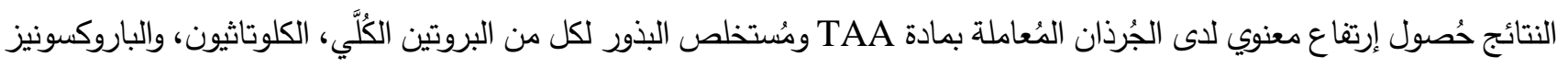
مُقارنة بمجموعة مُستخلصات اللب، والأوراق، وقد تم أثبات ذلك أيضاً عن طريق المقاطع النسيجية.

الكلمات المفتاحية: ثايوأسيتامايد، الفا فيتوبروتين، سرطان الخلايا الكبدية، نبات القشطة،المالونديالديهايد.

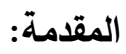

أورام الكبد الأولية Primary liver tumors هي ثاني أكثر الأسباب شيوعاً للوفاة بالسرطان عند الرجال في جميع أنحاء العالم، والسبب السادس عند النساء، وان سرطانات الخلايا الكبدية HCC Hepatocellular Carcinoma تعتبر من سرطانات الكبد الأساسية والأكثر شيوعًا والمسؤولة عن حوالي 1500 حالة وفاة سنويًا في الدول النامية[1]، وهي من أخطر الأمراض الخبيثة، وتمثل أورام الكبد نسبة من 80_90 \% من الاورام الكبدية الأولية وسرطانات الكبد الخبيثة ، ويمكن تقسيم الأورام السرطانية الى أنواع عقيدية

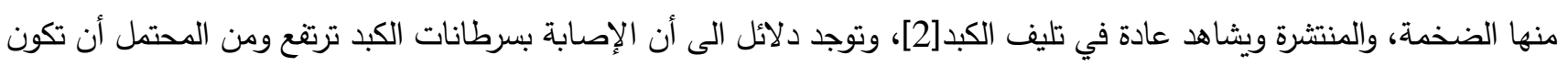

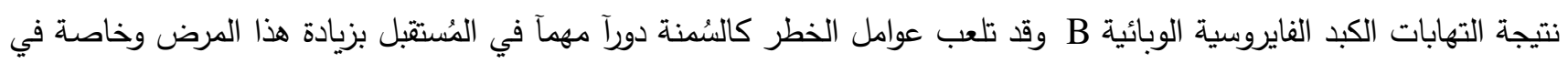

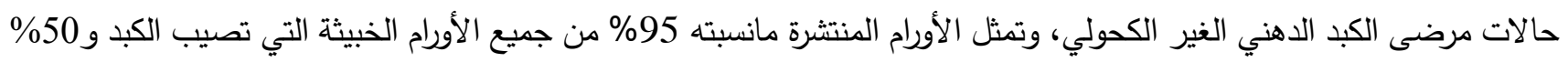
من الأورام الخبيثة الأخرى التي تتمثل بتليف الكبد، وان النوع المنتشر يتكون من عدد لايحصى من العقيدات الورمية الصغيرة والمنتشرة

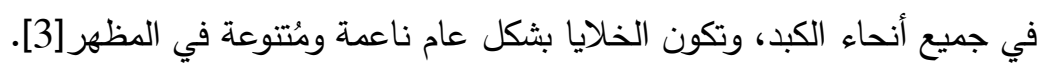

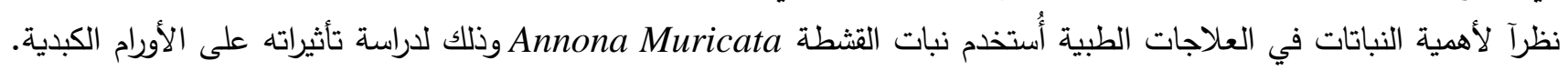

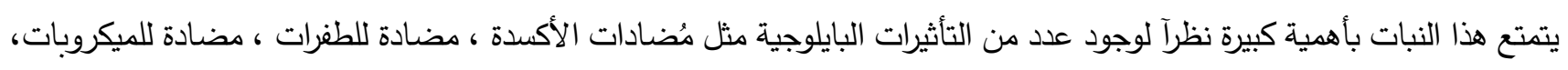

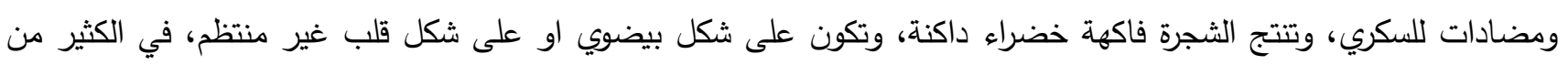

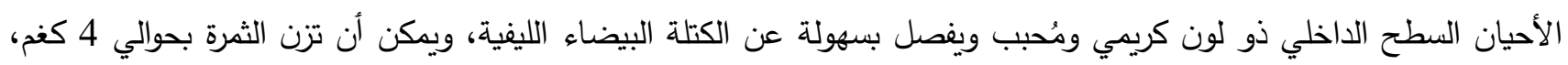
ويتكون من شرائح بيضاء ليفية تُحيط بأوعية طويلة وتكون البذور سوداء وبطول 1.25_2 سم اما القشور فتحتوي على اشوالك قصيرة

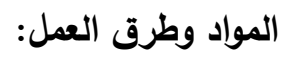

تم الحصول على نبات Annona Muricata من السوق المحلية، وأخذ 1 كيلوغرام منه ، ونظف من الثوائب والأتربة ووضع في

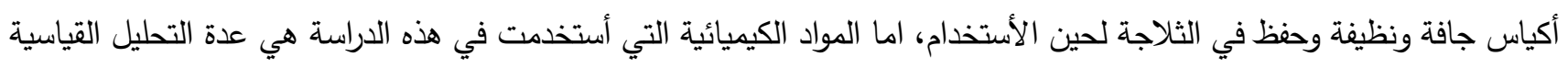
الجاهزة "Standard Kits"عدد 6 وهي: الفوسفاتيز القلوي من شركة Mybiosource ، البروتين الكلي من شركة 
Biolabo،البيلروبين الكلي Xpress Bio، الفا-فيتوبروتين من شركة_Kamiya Biomedical،الأسبارتيت ترانس أمينز من شركة Mybiosource ، والألنين ترانس أمينز من شركة Mybiosource وقيس فعالية أنزيم الباروكسونيز PON2 عن طريق قياس فعالية أنزيم اريل استريز وقدرت فعالية الأنزيم حسب طريقة [5] اذ يعمل الأنزيم على تحليل مادة فنيل أسيتيت الى فينول وحامض الخين الخليك

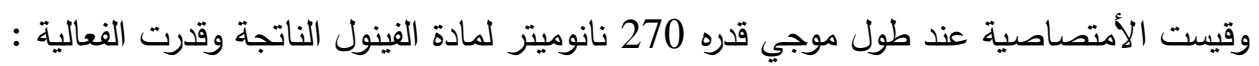
Phenol + Acetic Acid------_PON -------> Phenyl Acetate + $\mathrm{H}_{2} \mathrm{O}$

تم تقدير المالونديالديهايد عن طريق تفاعله مع حامض الثايوباربيتيورك Thiobarbetoric مع محلول Tri Chloro Acetic Acid مع 150 مايكروليتر من مصل دم الجرذان ، وقدر تركيز Glutathione في المصل وذلك بأستخدام طريقة كاشف آلمان

الحيوانات المستخدمة:

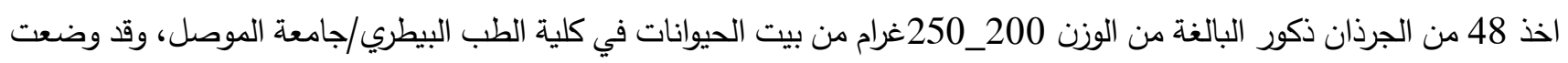
في أقفاص مجهزة ومعدة لهذا الغرض وزودت بالماء والعلف الحيواني الخاص بها وقد قُسمت الى ثمانية مجاميع، وتركت لمدة أسبوع واحد وذلك لأستيعاب الظروف المُختبرية من ضوء ودرجة حرارة ومن ثم أجراء عمليات الحقن والتجريع.

طريقة أستخلاص بذور نبات القشطة Annona Muricata

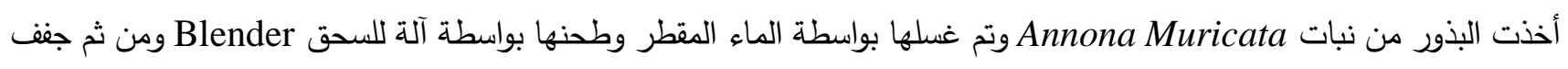
في فرن كهربائي عند 45 م وذلك لمدة يومين، ووضع حوالي100 غرام في 500 مل من الماء المقطر وتم وضعه في جهاز المُحرك

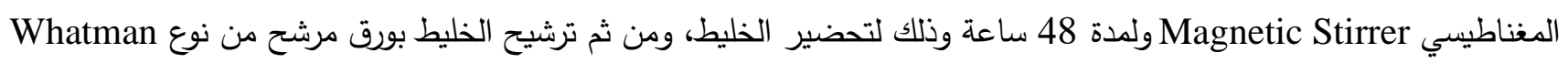

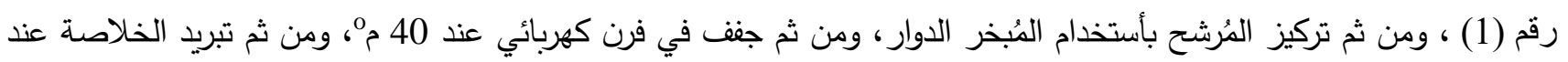
4 محتى تكون جاهزة للأستخدام [6]، ومن ثم يذوب 100 ملغم من المُستخلص في 2 مل مل من الماء المقطر والبدء بالتجربة.

: Annona Muricata طريقة استخلاص لب نبات القشطة سحق حوالي 50 غرام من اللب ووضع في 200 مل من الميثانول وذلك لمدة 48 ساعة في درجة حرارة الغرفة، ومن ثم رُكِّز بواسطة

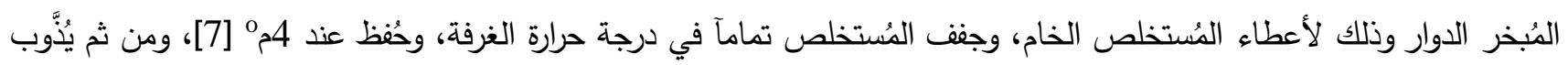
100 ملغم من المستخلص في 2مل من الماء المقطر لغرض البطاء وجئ باءلتجربة.

طريقة استخلاص أولق نبات القشطة Annona Muricata غسلت اوراق نبات Annona Muricata بالماء المقطر، وقطعت الى قطع صغيرة، ثم جفقت في درجة حرارة الغرفة، ووضع حوالي

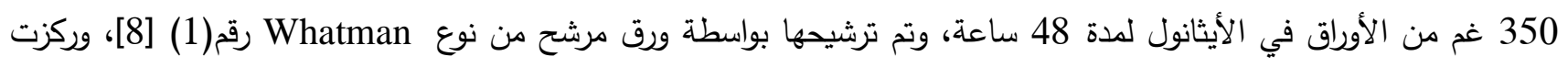

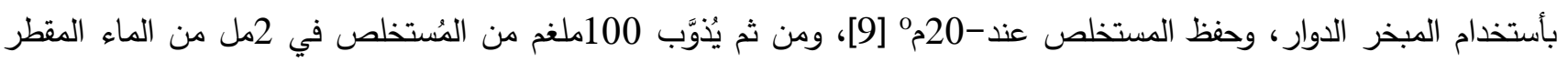
لغرض البدء بالتجربة. المواد والجرعات: الثايوأسيتاميد: اذيب غرام واحد من مادة الثايوأسيتاميد في 10 مل من الماء المقطر ، واعطيت الجرذان هذه المادة وذلك بتركيز 100 ملغم/كغ في

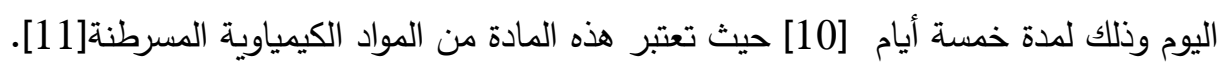


المستخلصات النباتية: بعد تحضير المستخلصات النباتية لنبات القشطة أعطيت الجرذان المستخلصات النباتية عن طريق التجريع بالفم وذلك بتركيز 500 ملغم/كغم يومياً ولمدة 28 يوماً [13]. تصميم التجربة: اخذ 48 من الجرذان الذكور نوع Wister وقسمت إلى ثمانية مجاميع لكل منها ست من الجرذان :

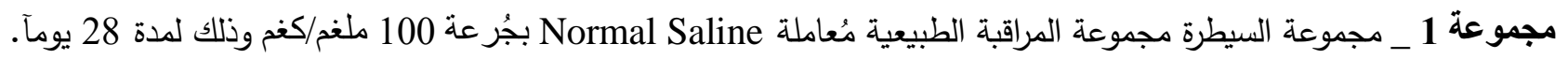
مجموعة 2 _ مجموعة تعامل بجرعات يومية من مادة TAA بجر عة 100 ملغم/كغم وذلك لمدة 5 أيام. مجموعة 3ــ مجموعة تعامل بمستخلص اللب بجرعة 500 ملغم/كغم ولمدة 28 يوماً. مجموعة 4_ مجموعة تعامل بمستخلص البذور بجرعة 500 ملغم/كغم يومياً ولمدة 28 يوماً. مجموعة 5_ مجموعة تعامل بمستخلص الأوراق بجرعة 500 ملغم/كغ ولمدة 28 يوماً. مجموعة 6_مجموعة تعامل بجرعات يومية من مادة TAA بجُرعة 100 ملغم/كغم ولمدة خمسة أيام ومن ثم تُعامل بمستخلص اللب بجرعة 500 ملغم/كغ وذلك لمدة 23 يومآ.

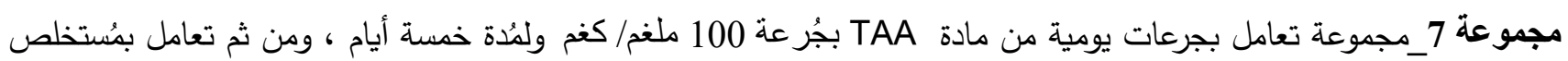
البذور بجرعة 500 ملغم/كغم وذلك لمدة 23 يومآ.

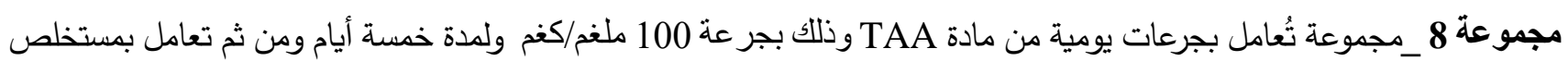
الأوراق بجرعة 500 ملغم/كغ وذلك لمئدة 23 يومآ.

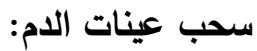
بعد أنتهاء المدة المحددة للتجربة ، سحب الدم الدم من الجرذان من جيب محجر العين وذلك بأستخدام أنابيب شعرية خاصة عن طريق

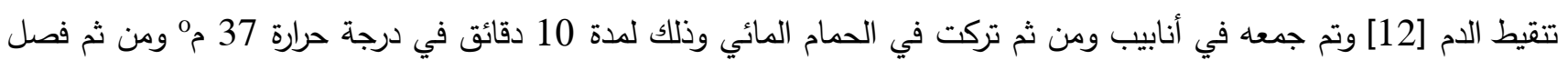

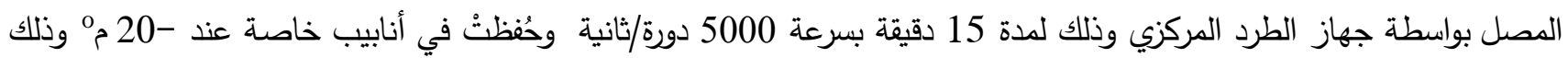
لأجراء الفحوصات.

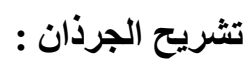
شرحت الجرذان بعد مرور 28 يومآ وذلك للتحري من إصابة الكبد نتيجة تأثره بالمادة الكيمياوية الثايوأسيتاميد وأخُذَ الكبد وتم حساب

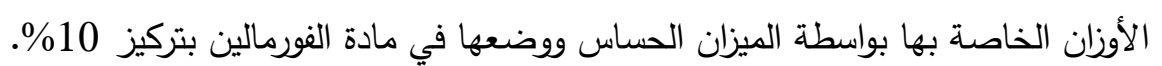

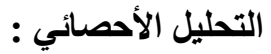
تم تحليل النتائج أحصائياً حيث تم وصف قيم المتغيرات الكيموحيوية وذلك بأستعمال المعدل Mean والأنحراف القياسي Standard Deviation حيث أستعمل أختبار Duncan Test بتحليل ANOVA وذلك لتحليل تأثير المتغيرات الكيموحيوية المدروسة[13]. 
الجدول رقم (1) يبين الأوزان الخاصة للجرذان المُعاملة بمادة الثايوأسيتاميد مع و بدون المستخلصات النباتية ، والمستخلصات لوحدها.

\begin{tabular}{|c|c|c|c|}
\hline $\begin{array}{c}\text { الوزن في نهاية } \\
\text { gram } \\
\text { التجربة }\end{array}$ & 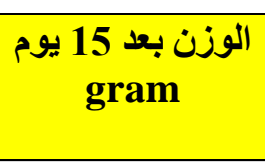 & الوزن بداية & المجاميع المعاملة \\
\hline $\begin{array}{c}277.666 \\
\pm \\
2.875 \\
\mathrm{~d}\end{array}$ & $\begin{array}{c}248.333 \\
\pm \\
27.890 \\
\text { bc }\end{array}$ & $\begin{array}{c}197.333 \\
\pm \\
7.633 \\
\mathrm{a}\end{array}$ & مجموعة السيطرة \\
\hline $\begin{array}{c}170 \\
\pm \\
20.918 \\
a\end{array}$ & $\begin{array}{c}195.333 \\
\pm \\
20.791 \\
a\end{array}$ & $\begin{array}{c}204.500 \\
\pm \\
10.213 \\
a\end{array}$ & مجموعة \\
\hline $\begin{array}{c}285.500 \\
\pm \\
25.743 \\
d\end{array}$ & $\begin{array}{c}269 \\
\pm \\
28.482 \\
c\end{array}$ & $\begin{array}{c}204.833 \\
\pm \\
5.742 \\
a\end{array}$ & مجموعة البذور \\
\hline $\begin{array}{c}252 \\
\pm \\
3.286 \\
c\end{array}$ & $\begin{array}{c}232.500 \\
\pm \\
8.216 \\
b\end{array}$ & $\begin{array}{c}196 \\
\pm \\
8.988 \\
\mathrm{a}\end{array}$ & مجموعة \\
\hline $\begin{array}{c}246.500 \\
\pm \\
45.461 \\
c\end{array}$ & $\begin{array}{c}238.500 \\
\pm \\
39.984 \\
b\end{array}$ & $\begin{array}{c}197.00 \\
\pm \\
9.444 \\
\mathrm{a}\end{array}$ & مجموعة الأوراق \\
\hline $\begin{array}{c}247.833 \\
\pm \\
16.666 \\
c\end{array}$ & $\begin{array}{c}204.666 \\
\pm \\
8.869 \\
a\end{array}$ & $\begin{array}{c}204.666 \\
\pm \\
13.140 \\
\mathrm{a}\end{array}$ & مجموعة البذور \\
\hline $\begin{array}{c}207.666 \\
\pm \\
6.314 \\
b\end{array}$ & $\begin{array}{c}203.500 \\
\pm \\
9.813 \\
\mathrm{a}\end{array}$ & $\begin{array}{c}200.166 \\
\pm \\
8.447 \\
a\end{array}$ & مجموعة اللب مع \\
\hline $\begin{array}{c}204 \\
\pm \\
10.973 \\
b\end{array}$ & $\begin{array}{c}204.833 \\
\pm \\
6.795 \\
a\end{array}$ & $\begin{array}{c}207.833 \\
\pm \\
8.588 \\
\mathrm{a}\end{array}$ & $\begin{array}{c}\text { مجموعة الأوراق } \\
\text { TAA + }\end{array}$ \\
\hline
\end{tabular}

إذ تثير الحروف d,c,b,a الى الفروق المَعنوية في الأوزان عند مُستوى الأحتمالية PS 0.05 ولكل المجاميع .

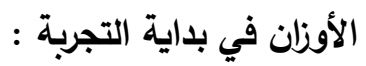
أثارت النتائج الخاصة بأوزان الجرذان كما هو مبين في الجدول بعدم وجود فروق معنوية بين أوزان الجرذان وذلك في بداية التجربة

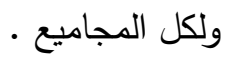


الأوزان بعد 15 يوم : أثارت النتائج الخاصة بالأوزان في منتصف التجربة كما مبين في الجدول رقم (1) الى حصول أنخفاض معنوي في أوزان الجرذان

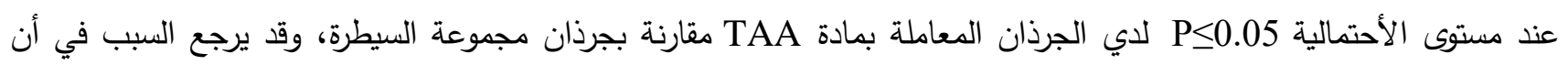

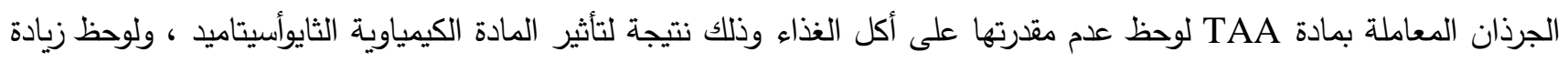
كبيرة في طرح الفضلات وتدهور في الحالة الصحية لاى الجرذان نتيجة للأصابة بالمرض وفقدان الثهية. حيث لوحظ ذلك عن عن طريق التيق

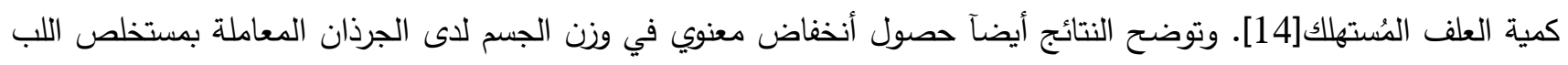
ومستخلص الأوراق مقارنة بمجموعة الجرذان المعاملة بمستخلص البذور، وقد يرجع السبب في ذلك الى المكونات النباتية الموجودة

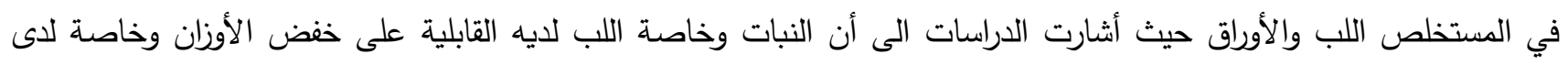

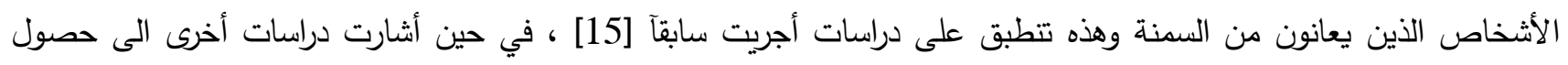

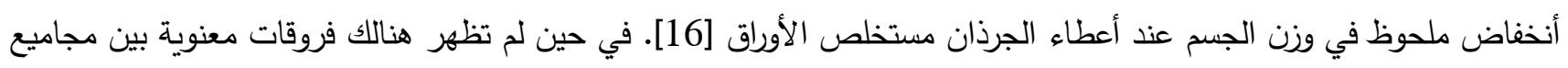

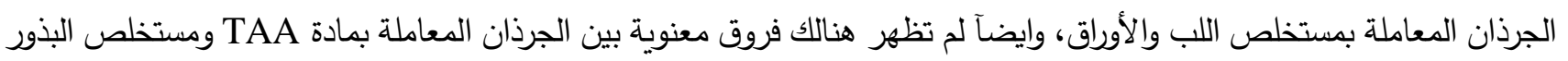
واللب والأوراق ومجموعة TAA.

الأوزان بعد 28 يوم : أشارت النتائج الخاصة بالأوزان في نهاية التجربة كما مبين في الجدول رقم (1) الى حُصول إنخفاض معنوي عند مُستوى

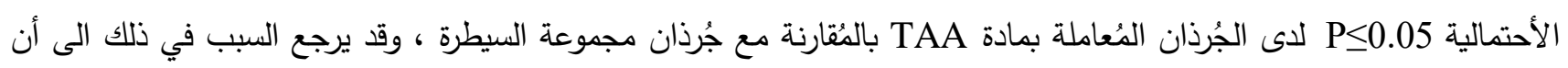

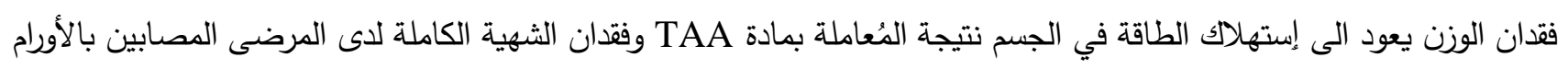
وهذا ينطبق على دراسات أجريت سابقآ[17]، بالأضافة الى أن مرضى الأورام السرطانية يعانون من إضطردابات في عمليات التمثيل

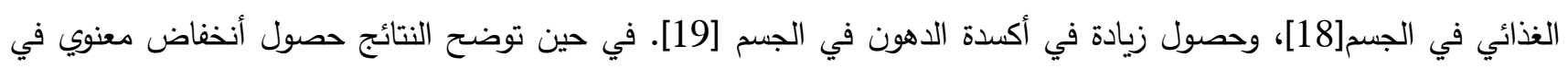
مجموعة الجرذان المعاملة بمستخلص اللب بالمقارنة بمجموعة الجرذان المعاملة بمستخلص البذور، ولم تظهر فروقات معنوية بين بين مجموعة الجرذان المعاملة بمستخلص البذور ومجموعة السيطرة. وتبين النتائج أيضاً حصول أنخفاض معنوي لاى الجرذان المعاملة

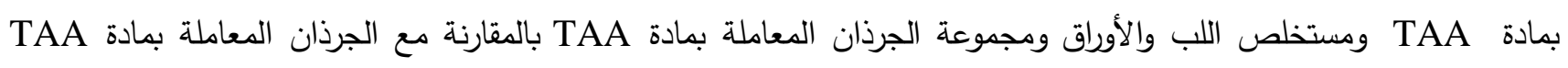

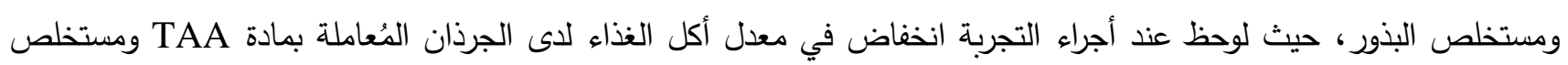
اللب والأوراق وهذا ينطبق على دراسات أجريت سابقاً حيث أشارت الى حُصول إنخفاض في وزن فئن الجسم نتيجة المعاملة

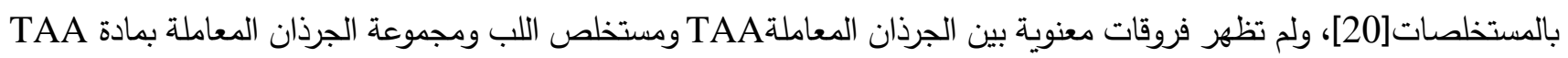
ومستخلص الأوراق، ولم تظهر فروقات معنوية أيضا بين مجاميع الجرذان المعاملة بمستخلص اللب والأوراق. 
الجدول رقم (2) يبين أوزان الكبد النسبية بوحدة mg/100g من وزن الجسم للجرذان المعاملة بمادة الثايوأسيتاميد مع و بدون المستخلصات النباتية 20 والمستخلصات النباتية لوحدها.

\begin{tabular}{|c|c|}
\hline أوزان الكبد النسبية & $\begin{array}{l}\text { المجاميع المعاملة } \\
\text { Mean+S.D }\end{array}$ \\
\hline $\begin{array}{c}2257.666 \\
\pm \\
160.037 \\
\text { a }\end{array}$ & مجموعة السيطرة \\
\hline $\begin{array}{c}4617.500 \\
\pm \\
265.855 \\
\mathrm{e}\end{array}$ & مجموعة TAA \\
\hline $\begin{array}{c}2231.666 \\
\pm \\
197.523 \\
\mathrm{a}\end{array}$ & مجموعة البذور \\
\hline $\begin{array}{c}2356 \\
\pm \\
205.945 \\
a b\end{array}$ & مجموعة اللب \\
\hline $\begin{array}{c}2589.666 \\
\pm \\
230.265 \\
b\end{array}$ & مجموعة الأوراق \\
\hline $\begin{array}{c}2838.666 \\
\pm \\
158.466 \\
\text { c }\end{array}$ & + البذورTAAمجموعة \\
\hline $\begin{array}{c}3184 \\
\pm \\
249.880 \\
\mathrm{~d} \\
\end{array}$ & + اللب TAAمجموعة \\
\hline $\begin{array}{c}3121 \\
\pm \\
106.425 \\
\mathrm{~d} \\
\end{array}$ & + الأوراق TAA مجموعة \\
\hline
\end{tabular}

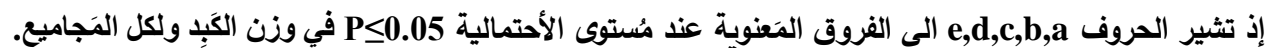

Relative liver weights:

اوزان الكبد النسبية :

تبين النتائج كما موضح في الجدول رقم (2) لأوزان الكبد النسبية للجرذان المعاملة بمادة TAA حصول أرتفاع معنوي عند مستوى الأحتمالية P<0.05 في وزن الكبد مقارنة بمجموعة السيطرة ، وقد يرجع السبب في ذلك للمادة الكيمياوية TAA والتي تسبب سرطان الكبد، وحدوث التورمات ، وتجمع الدم فيه ، وقد أشارت دراسات سابقة الى حدوث تضخم في الكبد نتيجة لأستخدام المادة الكيمياوية المسرطنة TAA] [21. ولم تظهر هنالك فروق معنوية لاى الجرذان المعاملة بمستخلص البذور ومجموعة الجرذان المعاملة بمستخلص اللب ومجموعة الجرذان المعاملة بمستخلص الأوراق ومجموعة السيطرة. في حين حصل أنخفاض معنوي في وزن الكبد لدى الجرذان 
المعاملة بمادة TAA ومستخلص البذور مقارنة بمجموعة الجرذان المعاملة بمادة TAA ومستخلص اللب ومستخلص الأوراق ومجموعة الجرذان المعاملة بمادة TAA ، وقد يرجع السبب الى المكونات الفعالة في البذور مثل الأحماض الأمينية ، الفينولات ،

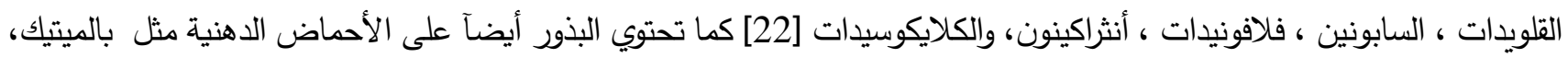
ستاريك، بالميتوليك، أوليك، لينوليك [23] وهذه المكونات المفيدة قد تعمل كمضادات أكسدة والتي قد تعمل على تحسين تحين حالة الكبد

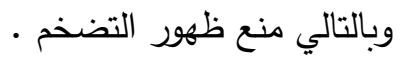

قياس بعض المتغيرات الكيموحيوية في مصل الام : الجدول رقم (3) يبين بعض المتغيرات الكيموحيوية التي قيست في مصل الدم للجرذان المعاملة بمادة الثايوأسيتاميد مع و بدون المستخلصات النباتية ، والمستخلصات النباتية لوحدها .

\begin{tabular}{|c|c|c|c|c|c|c|c|c|}
\hline \multicolumn{8}{|c|}{ المجاميع المعاملة } & \multirow{3}{*}{ المتغيرات الكيموحيوية } \\
\hline مجموعة & مجموعة & مجموعة & مجموعة & مجموعة & مجموعة & مجموعة & مجموعة & \\
\hline $\begin{array}{c}\text { الأوراق } \\
\text { TAA } \\
\text { TAA }\end{array}$ & $\begin{array}{l}\text { اللب مع } \\
\text { TAA }\end{array}$ & $\begin{array}{c}\text { ميذور } \\
\text { TAA }\end{array}$ & الأوراق & اللب & البذور & TAA & السيطرة & \\
\hline $\begin{array}{c}7.564 \\
\pm\end{array}$ & $\begin{array}{c}6.800 \\
\pm\end{array}$ & $\begin{array}{c}11.842 \\
\pm\end{array}$ & $\begin{array}{c}9.561 \\
\pm\end{array}$ & $\begin{array}{l}9.611 \\
\pm\end{array}$ & $\begin{array}{c}16.271 \\
\pm\end{array}$ & $\begin{array}{c}5.119 \\
\pm\end{array}$ & $\begin{array}{c}12.811 \\
\pm\end{array}$ & $\begin{array}{c}\text { Total Proteins } \\
\text { g/dl }\end{array}$ \\
\hline 0.462 & 1.840 & 1.356 & 0.385 & 0.688 & 1.864 & 1.457 & 0.986 & \\
\hline $\mathrm{b}$ & $\mathrm{b}$ & $\mathrm{d}$ & c & $\mathrm{c}$ & $\mathrm{e}$ & $\mathrm{a}$ & $\mathrm{d}$ & \\
\hline $\begin{array}{c}2.806 \\
\pm\end{array}$ & $\begin{array}{l}3.001 \\
\pm\end{array}$ & $\begin{array}{c}1.946 \\
\pm\end{array}$ & $\begin{array}{c}2.650 \\
\pm\end{array}$ & $\begin{array}{c}1.547 \\
\pm\end{array}$ & $\begin{array}{l}0.714 \\
\pm\end{array}$ & $\begin{array}{l}4.434 \\
\pm\end{array}$ & $\begin{array}{c}1.294 \\
\pm\end{array}$ & $\begin{array}{l}\text { Total Bilirubin } \\
\text { (mg/dl) }\end{array}$ \\
\hline 0.776 & 0.505 & 0.198 & 0.406 & 0.387 & 0.067 & 0.427 & 0.265 & \\
\hline $\mathrm{d}$ & $\mathrm{d}$ & $\mathrm{c}$ & $\mathrm{d}$ & $\mathrm{bc}$ & $\mathrm{a}$ & $\mathrm{e}$ & $\mathrm{b}$ & \\
\hline 78.250 & 67.500 & 52.050 & 7.592 & 7.592 & 8.725 & 96.666 & 5.443 & $(\mathbf{A F P})$ \\
\hline \pm & \pm & \pm & \pm & \pm & \pm & \pm & \pm & (ng/ml) \\
\hline 1.369 & 2.409 & 3.779 & 0.803 & 0.803 & 0.292 & 1.366 & 0.841 & \\
\hline $\mathrm{e}$ & $\mathrm{d}$ & $\mathrm{c}$ & $a b$ & $a b$ & $\mathrm{~b}$ & $\mathrm{f}$ & $\mathrm{a}$ & \\
\hline 1.200 & 2.100 & 3.527 & 3.268 & 2.605 & 5.595 & 1.177 & 4.103 & Glutathione \\
\hline \pm & \pm & \pm & \pm & \pm & \pm & \pm & \pm & $\mu$ mole/l \\
\hline 0.000 & 0.219 & 0.472 & 0.371 & 0.115 & 0.598 & 0.169 & 0.365 & \\
\hline $\mathrm{a}$ & $\mathrm{b}$ & $\mathrm{d}$ & $\mathrm{d}$ & $\mathrm{c}$ & $\mathrm{f}$ & $\mathrm{a}$ & $\mathrm{e}$ & \\
\hline 8.550 & 7.850 & 6.100 & 5.200 & 5.300 & 4.413 & 8.500 & 4.300 & \\
\hline \pm & \pm & \pm & \pm & \pm & \pm & \pm & \pm & Malondialdehyde \\
\hline 0.054 & 0.822 & 0.219 & 1.179 & 0.000 & 0.436 & 1.163 & 0.536 & umole/l \\
\hline $\mathrm{e}$ & $\mathrm{e}$ & d & bc & $\mathrm{cd}$ & $\mathrm{ab}$ & $\mathrm{e}$ & $\mathrm{a}$ & \\
\hline
\end{tabular}

حيث تثير الحروف f,e,d,c,b,a الى الفروق المنوية عند مستوى الأحتمالية PS0.05 للمتغيرات الكيموحيوية التي قيست في مَصل الام ولكل المجاميع البروتين الكلي : البرت أظهرت النتائج كُما مبين في الجدول رقم (3) حُصول أنخفاض معنوي لتراكيز البروتين الكلي في مصل دم الجرذان المعاملة بمادة

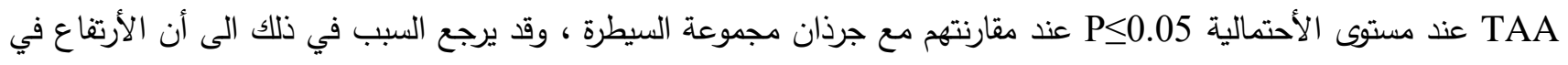
مستوى الكرب التأكسدي نتيجة المعاملة بمادة TAA أدى الى زيادة تعرض جلى الجزيئات الحيوية للأكسدة ومنها البروتين وتكوين هيدروبيروكسيدات البروتين [24]. وعند تعرض البروتين الى أنواع الأوكسجين الفعالة ROS وبوجود الأوكسجين فأنه يؤدي الى حدوث تغيرات في الجزيئات الحيوية مثل أكسدة الأحماض الدهنية ، وحدوث تغيرات في الأواصر بين السلاسل وتكون مجاميع جديدة وهي 
الهيدروبيروكسيدات، وهي تؤدي الى أكسدة البروتين والتي لها دور كبير في أحداث الأورام وذلك لتفاعلها مع الحامض النووي الرايبوزي منقوص الأوكسجين DNA واحداث الطفرات الوراثية فيها[25]. وأظهرت نتائج الدراسة ايضآ أرتفاعآ معنويآ في تركيز البروتين الكلي

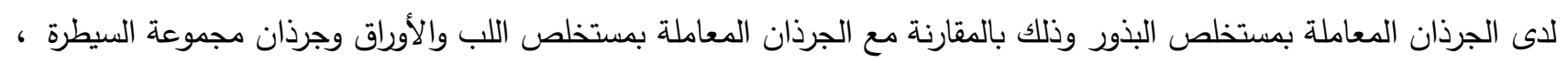
ولم تظهر فروقات معنوية بين الجرذان المعاملة بمستخلص اللب ومستخلص الأوراق. كما أوضحت النتائج بأن الجرذان المعاملة بمادة TAA ومستخلص البذور حصل فيها أرتفاع معنوي وذلك بالمقارنة مع الجرذان المعاملة بمادة TAA ومستخلص اللب ومجموعة

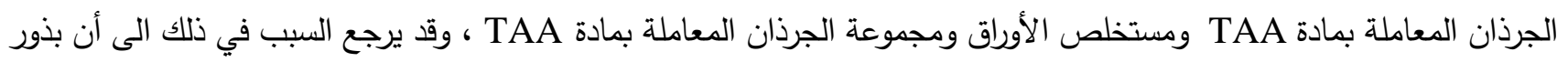

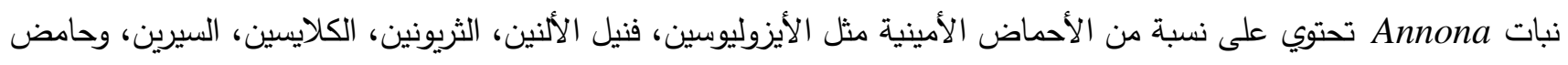

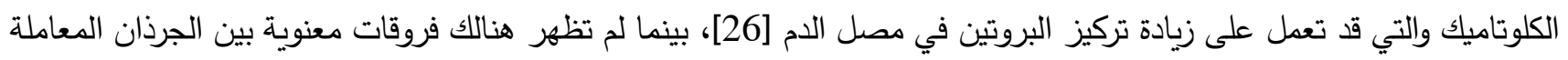

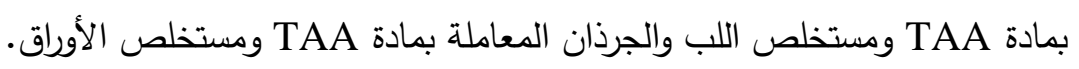

البيلروبين الكلي: تصني:

P تبين النتائج لقياس تركيز البيلروبين الكلي في الجرذان المعاملة بمادة TAA حصول أرتفاع معنوي عند مستوى الأحتمالية مقارنة بمجوعة جرذان السيطرة، وقد يرجع سبب الأرتفاع في تركيز البيلروبين الى حصول تلفين في الخلايا الكبدية وطرح البليروبين

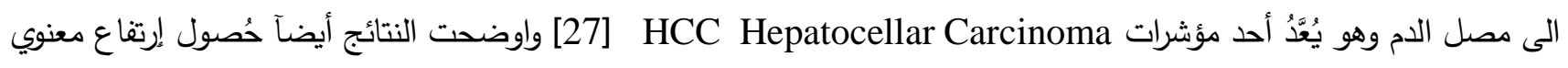
للدى الجرذان المعاملة بمستخلص اللب والأوراق مقارنة بمجموعة الجرذان المعاملة بمستخلص البذور ، وقد يرجع السبب في ذلك الى الى

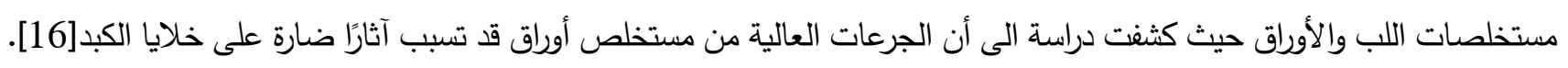

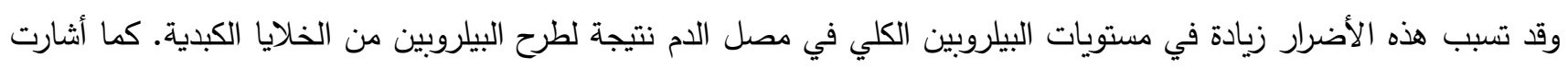

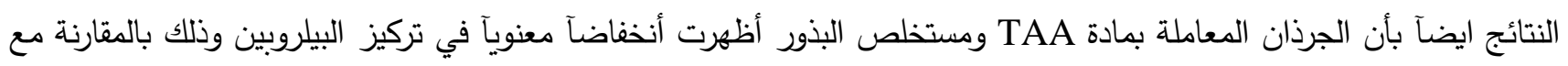
جرذان المعاملة بمادة TAA ومستخلص اللب والأوراق والجرذان المعاملة بمادة TAA، وقد يرجع السبب في ذلك الى أن البذور تحتوي على مركبات الأسيتوجينين ويلعب دورًا كحاجز وقاتل للخلايا السرطانية بثكل انتقائي لأنه يمكن أن يكثف وئف ويميز بين بين الخلايا

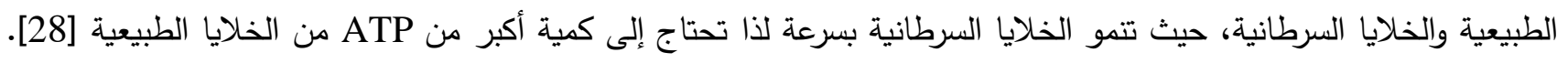

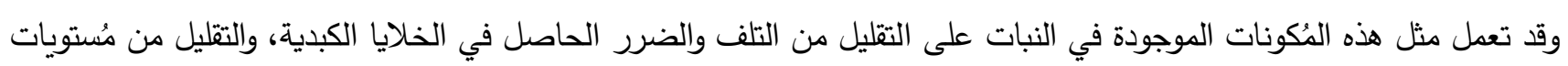
البيلروبين في مَصل الدم.

\section{الفا فيتو بروتين :}

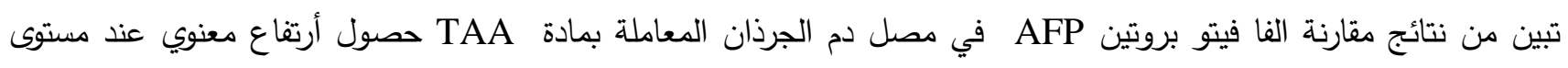

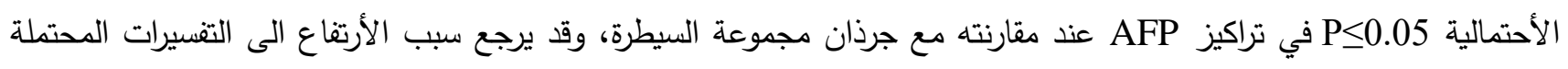

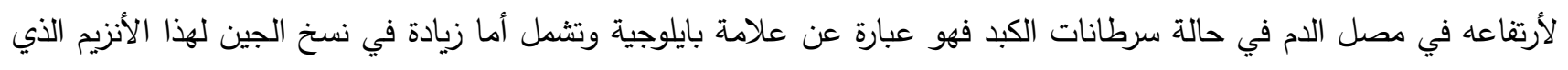

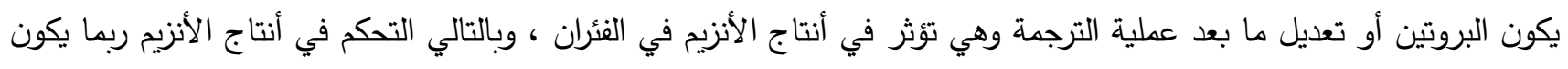

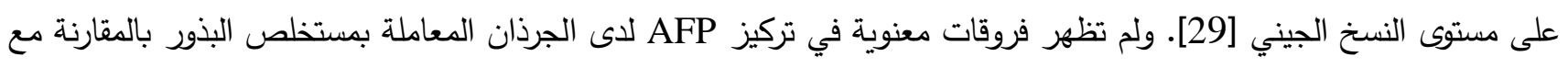
مجموعة الجرذان المعاملة بمستخلص اللب ومستخلص الأوراق. بينما ظهر فرق معنوي بين مجموعة البذور مقارنة بمجموعة السيطرة.

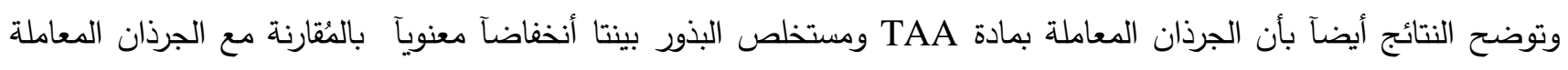

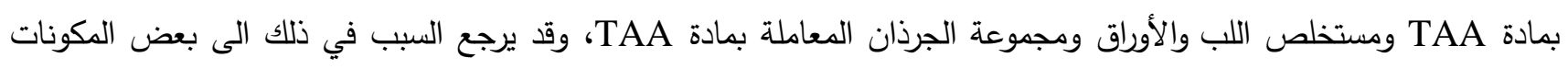

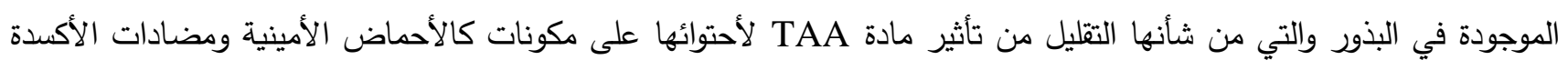

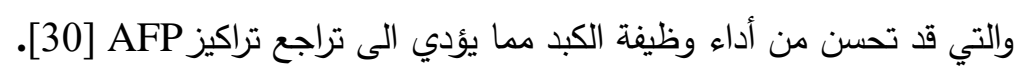


أثارت نتائج الدراسة عند مقارنة تراكيز الكلوتاثيون GSH في مصل دم الجرذان المعاملة بمادة TAA حصول أنخفاض معنوي عند مستوى الأحتمالية PSC عند مقارنتهم مع جرذان مجموعة السيطرة وقد يرجع سبب الأنخفاض في مستويات

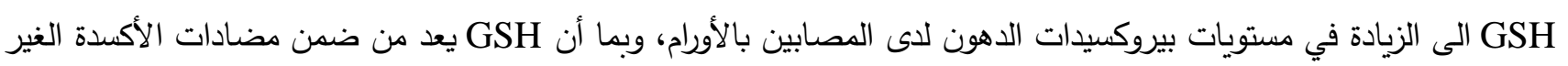

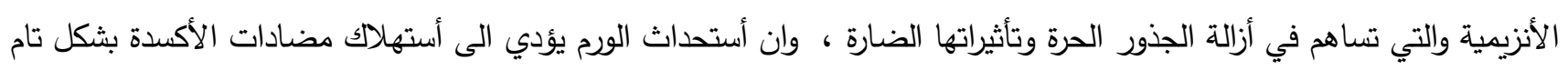

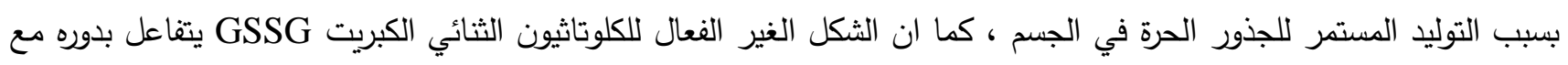

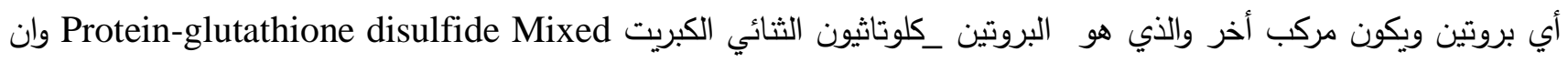

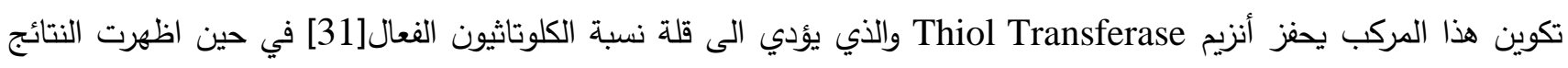
أرتفاعآ معنويآ في تركيز GSH لدى الجرذان المعاملة بمستخلص البذور مقارنة بالجرذان المعاملة بمستخلص اللب والأوراق ومجموعة

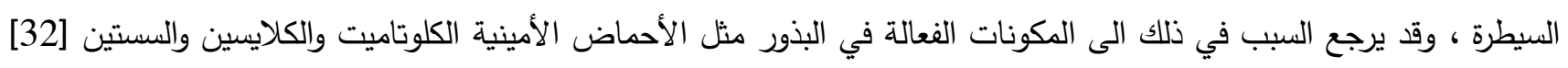

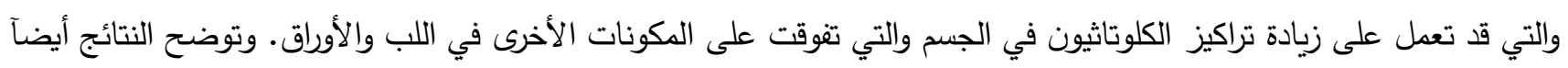

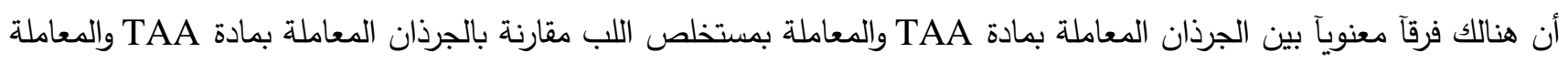

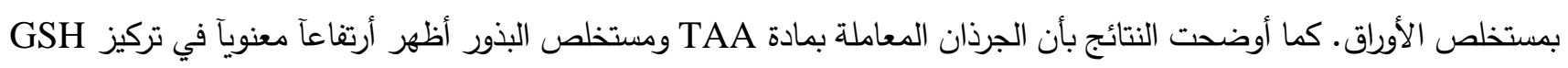

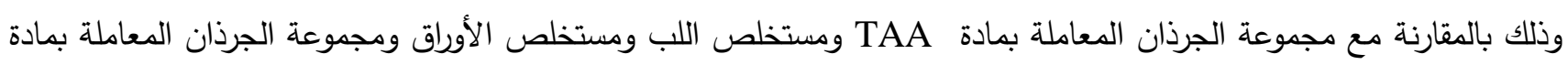
TAA وقد يرجع السبب في ذلك الى أن بذور نبات Annona تمتلك مضادات الأكسدة الأنزيمية والغير الأنزيمية[33] كما تحتوي

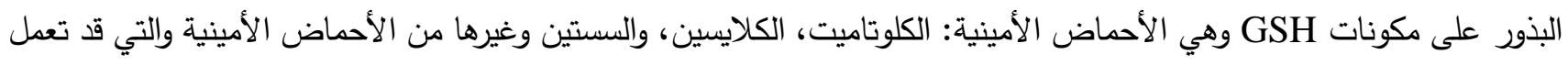

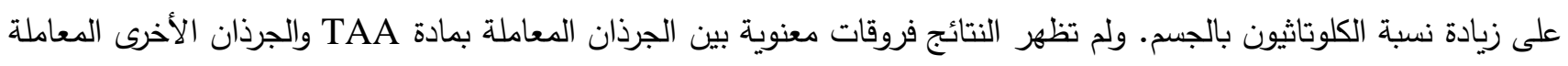
بمادة TAA ومستخلص زلادة نسبة الأوراق.

\section{المالونديالديهايد :}

أستنادا الى النتائج ، تبين أرتفاع معنوي عند مستوى الأحتمالية PAA

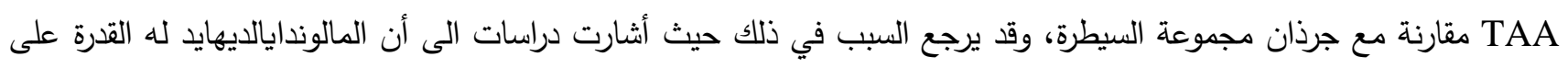

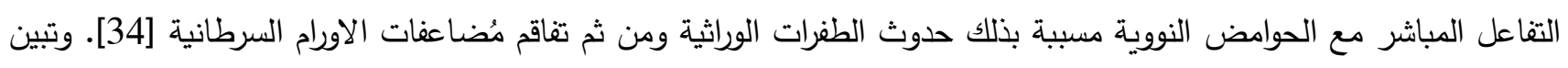
النتائج أيضاً حصول أنخفاض معنوي لاى الجرذان المعاملة بمستخلص البذور وذلك بالمقارنة مع مجموعة اللب ومجموعة الأوراق وتبين النتائج بأن هنالك أنخفاضاً معنويآ MDA لاى الجرذان المعاملة بمادة TAA ومستخلص البذور وذلك بالمقارنة مع جرذان

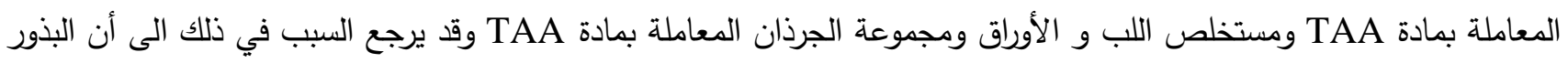

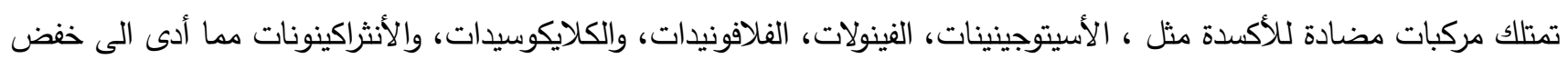
من نر اكيز المالونديالايهايد[22] 
الجدول رقم (4) يبين بعض الأنزيمات الكبدية التي قيست في مصل الام للجرذان المعاملة بمادة الثايوأسيتامايد مع وبدون المستخلصات النباتية ،

\begin{tabular}{|c|c|c|c|c|c|c|c|c|}
\hline \multicolumn{8}{|c|}{ المجاميع المعاملة } & \multirow[t]{3}{*}{ المتغيرات } \\
\hline مجموعة & اللب مع & مجموعة & مجموعة & مجموع & مجموعة & مجمو عة & مجموعة & \\
\hline +الأوراق + & TAA & $\begin{array}{c}\text { البذور مع } \\
\text { TAA }\end{array}$ & الاوراق & اللب & البذور & TAA & السيطرة & \\
\hline 39.350 & 47.54 & 62.328 & 134.92 & 92.70 & 97.796 & 35.648 & 128.14 & \\
\hline \pm & 4 & \pm & 3 & 9 & \pm & \pm & & Paroxona \\
\hline 0.543 & \pm & 1.965 & \pm & \pm & 0.449 & 1.570 & \pm & $\mathbf{S}$ \\
\hline $\mathrm{a}$ & $\begin{array}{c}4.568 \\
b\end{array}$ & $\mathrm{c}$ & $\begin{array}{c}3.554 \\
\mathrm{e}\end{array}$ & $\begin{array}{c}0.459 \\
\mathrm{~d}\end{array}$ & $\mathrm{~d}$ & $\mathrm{a}$ & $\begin{array}{c}17.147 \\
\mathrm{e}\end{array}$ & IU/L \\
\hline 128.733 & 138.5 & 94.808 & 95.021 & 76.33 & 49.350 & 151.900 & 62.255 & Alkaline \\
\hline \pm & 92 & \pm & \pm & 3 & \pm & \pm & \pm & Phosphat \\
\hline 1.096 & \pm & 6.177 & 4.074 & \pm & 3.012 & 3.178 & 1.122 & es \\
\hline $\mathrm{e}$ & $\begin{array}{c}8.784 \\
f\end{array}$ & $\mathrm{~d}$ & d & $\begin{array}{c}5.551 \\
\mathrm{c}\end{array}$ & $\mathrm{a}$ & $\mathrm{g}$ & $\mathrm{b}$ & IU/L \\
\hline 66.500 & 64.00 & 61.500 & 51.550 & 52.50 & 40.600 & 114.666 & 54.166 & AST \\
\hline \pm & 0 & \pm & \pm & 0 & \pm & \pm & \pm & IU/L \\
\hline 3.834 & \pm & 1.643 & 1.698 & \pm & 2.738 & 4.920 & 3.430 & \\
\hline $\mathrm{c}$ & $\begin{array}{c}6.573 \\
\mathrm{c}\end{array}$ & $\mathrm{c}$ & $\mathrm{b}$ & $\begin{array}{c}2.738 \\
b\end{array}$ & $\mathrm{a}$ & $\mathrm{d}$ & $\mathrm{b}$ & \\
\hline 80.500 & 73.00 & 49.953 & 61.500 & 49.00 & 32.346 & 145.000 & 41.166 & ALT \\
\hline \pm & 0 & \pm & \pm & 0 & \pm & \pm & \pm & IU/L \\
\hline 2.739 & \pm & 1.934 & 1.643 & \pm & 2.564 & 11.832 & 5.742 & \\
\hline $\mathrm{f}$ & $\begin{array}{c}5.477 \\
\mathrm{e}\end{array}$ & $\mathrm{c}$ & $\mathrm{d}$ & $\begin{array}{c}4.382 \\
c\end{array}$ & $\mathrm{a}$ & $\mathrm{g}$ & b & \\
\hline
\end{tabular}

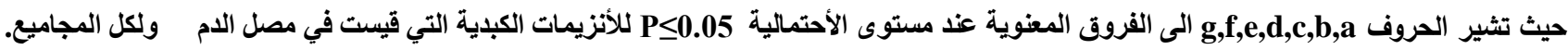

أنزيم الباروكسونيز

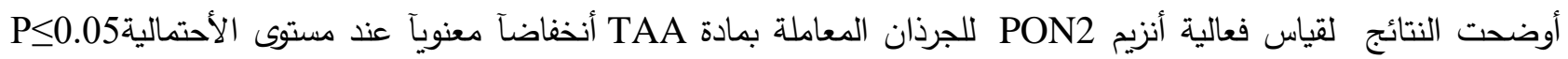
بالمقارنة مع جرذان مجموعة السيطرة، وقد يرجع السبب في أنخفاض فعالية الأنزيم الى أن التولد المستمر للجذور الحرة في الجسم

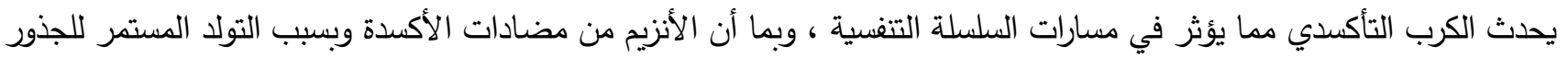
فتنخفض فعالية الأنزيم [35]. و توضح النتائج أيضاً حُصول أرتفاع معنوي في فعالية الأنزيم للى الجرذان المعاملة بمستخلص الأوراق ومجموعة جرذان السيطرة مقارنة بمجموعة الجرذان المعاملة بمستخلص البذور واللب، وقد يرجع السبب في ذلك الى المكونات الموجودة في الأوراق ، وأشارت دراسات أخرى الى أن أوراق نبات Annona تحتوي على عدد من الأحماض الأمينية والتي قد تعمل

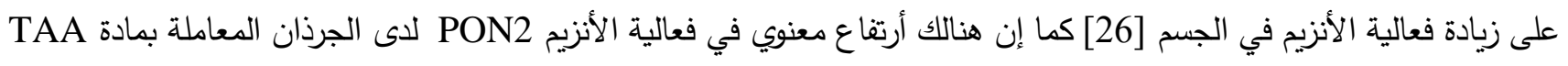

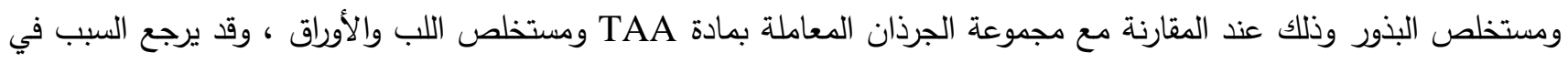
ذلك الى بذور نبات Annona تمتلك مضادات الأكسدة الأنزيمية والغير الأنزيمية[33] والتي قد تساعد في الدحافظة وزيادة فعالية الأنزيم في الجسم، ولم تظهر فروقات معنوية بين مجموعة الجرذان المعاملة بمادة TAA ومُستخلص الأوراق ومجموعة الجرذان المعاملة بمادة TAA. بينما ظهرت فروق معنوية أخرى بين الجرذان المعاملة بمادة TAA ومستخلص اللب والذي أظهر أرتفاعاً معنوياً مقارنة بمجموعة الجرذان المعاملة بمادة TAA ومستخلص الأوراق، وقد يرجع السبب في ذلك الى أن اللب يحتوي على بلى بلى بلى 
مضادات الأكسدة الأنزيمية حيث أن هذه المواد تعتبر سامة وبشكل أنتقائي ضد مختلف أنواع الخلايا السرطانية [36]، والتي قد تعمل على التحسين من حالة الحيوانات المرضية وزيادة فعالية الأنزيم بالجسم. الفوسفاتيز القلوي: تبين النتائج عند مقارنة أنزيم ALP في مصل دم الجرذان المعاملة بمادة TAA حصول أرتفاع معنوي عند مستوى الأحتمالية 0.05 في فعالية الأنزيم عند مقارنته مع جرذان مجموعة السيطرة ، وقد يرجع سبب الأرتفاع في فعالية الأنزيم الى أستخدام مادة

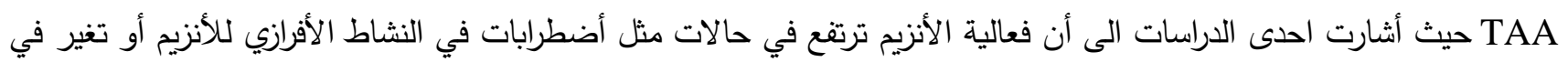

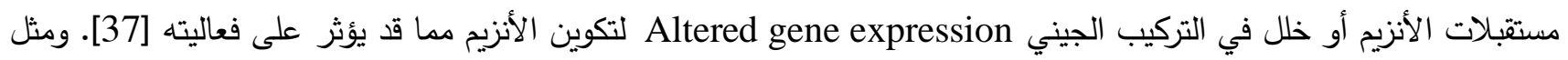

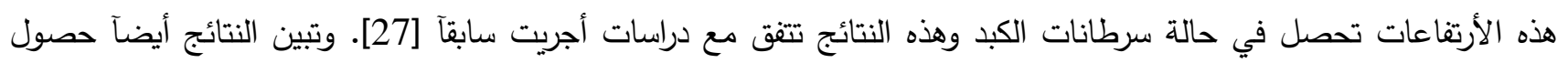
أنخفاض معنوي في فعالية الأنزيم لاى الجرذان المعاملة بمستخلص البذور بالمقارنة مع مستخلص الأوراق ومجموعة الجرذان المعاملة

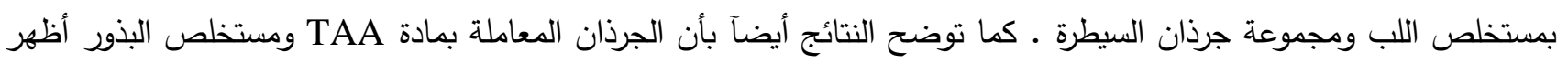

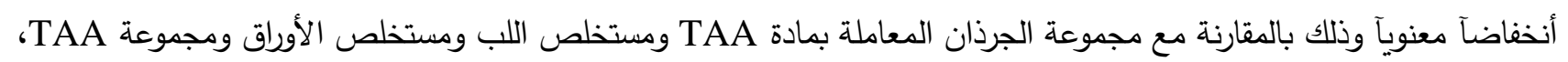
في حين توضح النتائج حصول أنخفاض معنوي مع الجرذان المعاملة بمادة TAA ومستخلص الأوراق وذلك بالمقارنة مع الجرذان المعاملة بمادة TAA ومستخلص اللب، وقد يرجع السبب في ذلك الى أن المستخلصات تمتلك مركبات فعالة مثل الفلافونيدات،

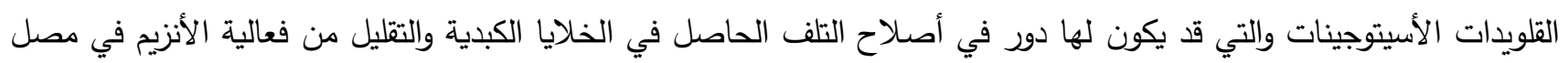

الأسبارتيت ترانس امينز: تشير نتائج الدراسة الى حصول زيادة في نثاط AST اي أرتفاع معنوي عند مستوى الأحتمالية PA

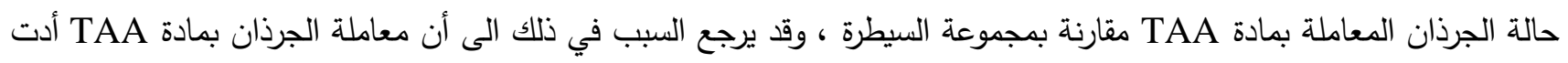

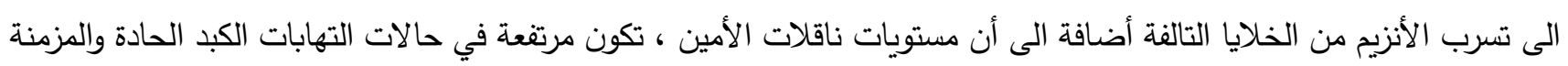

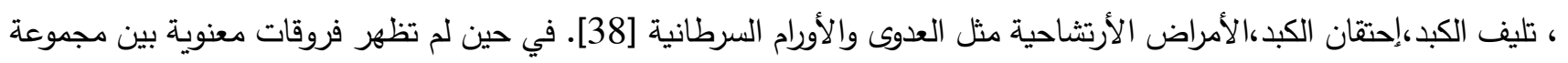

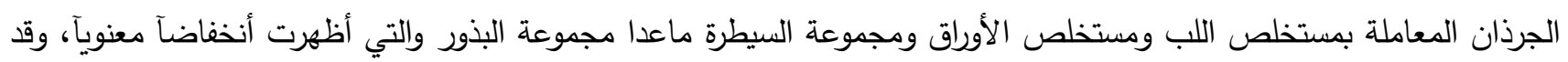
يرجع السبب الى أن البذور تحتوي على كمية من الأسيتوجينينات[39] والتي يصعب التعامل معها كيميائياً مما يثكل مشكلة في

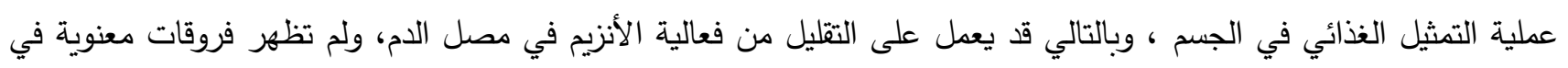

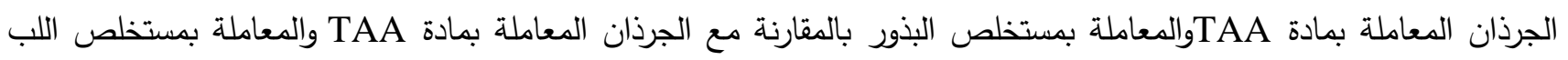
والأوراق.

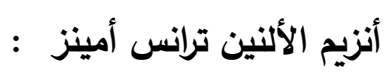
أثارت النتائج الى حصول أرتفاع معنوي عند مستوى الأحتمالية PS

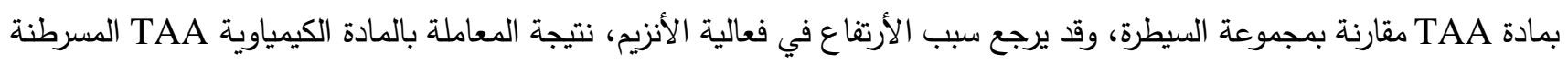

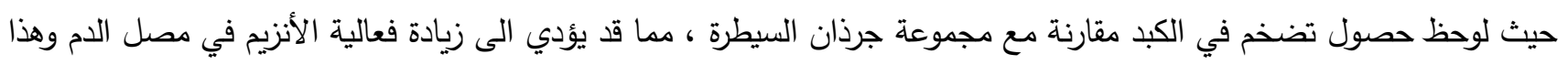

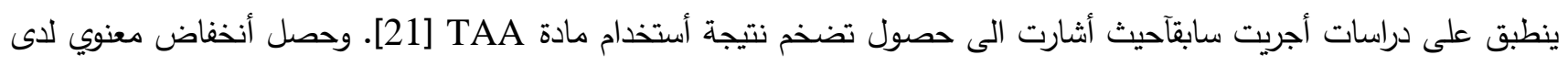
الجرذان المعاملة بمستخلص البذور وذلك بالمقارنة مع الجرذان المعاملة بمستخلص الأوراق ومستخلص اللب في حين أنخفضت فعالية

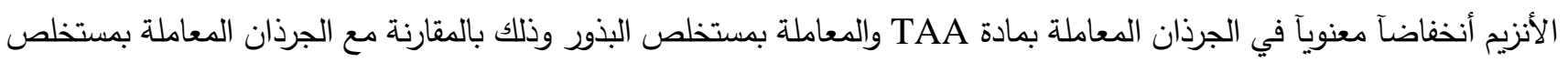
اللب والأوراق، والمجموعة المعاملة بمادة TAA وتبين النتائج أيضاً حصول أختلاف معنوي بين الجرذان المعاملة بمادة TAA 
ومستخلص اللب مقارنة بمجموعة الجرذان المعاملة بمادة TAA ومستخلص الأوراق، وقد يرجع السبب في ذلك الى المكونات الموجودة في اللب والبذور مثل الأسيتوجينينات[39]، والتي تخفض من تكوين الطاقة في المايتوكندريا وحرمان الخلية من الطاقة، كما قد يعزى الطى الى أن الأسيتوجينينات ترتبط مع بعض أنواع مستقبلات النمو السرطاني على سطح الخلية وتعمل على غلقها وإيقاف نموها وهذا يؤدي الى خلل في أفراز الأنزيم مما قد يظهر أنخفاض مُستواه. ولم تظهر فروقات الات معنوية بين مجموعة الجرذان المعاملة بمستخلص

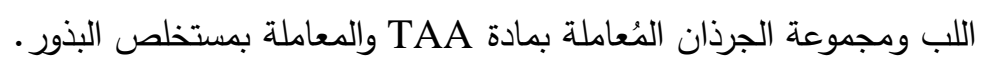

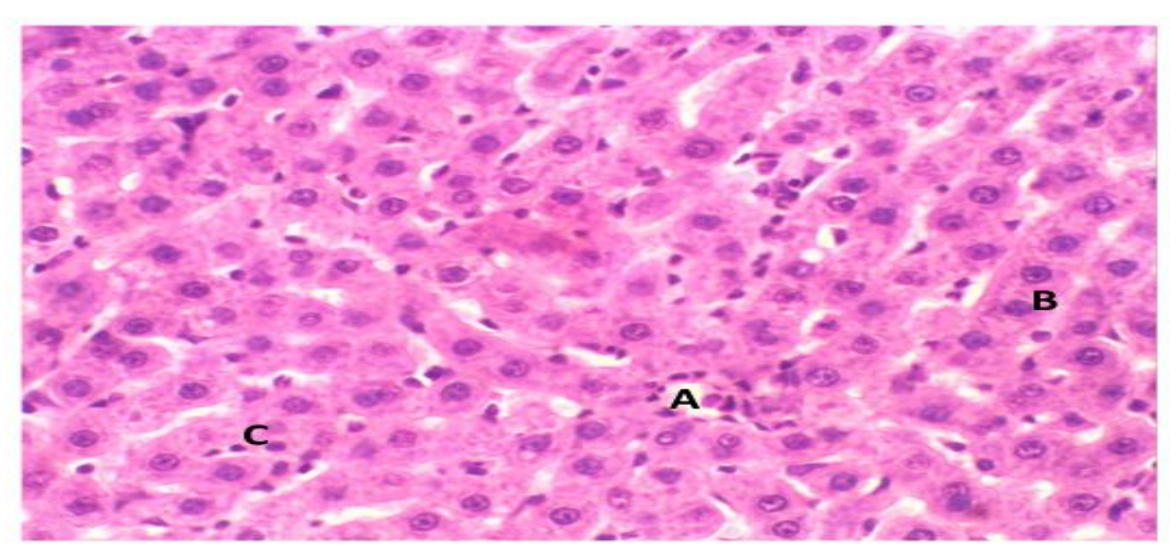

A الثكل رقم (1) مقطع نسيجي للكبد جرذ للمجموعة السيطرة: مقطع نسيجي للكبد جرذ للمجموعة السيطرة يظهر النسيج السوي للكبد ومبينا الوريد

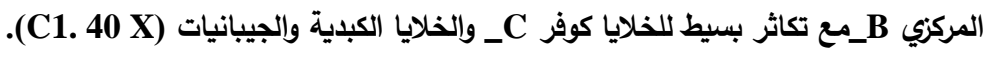

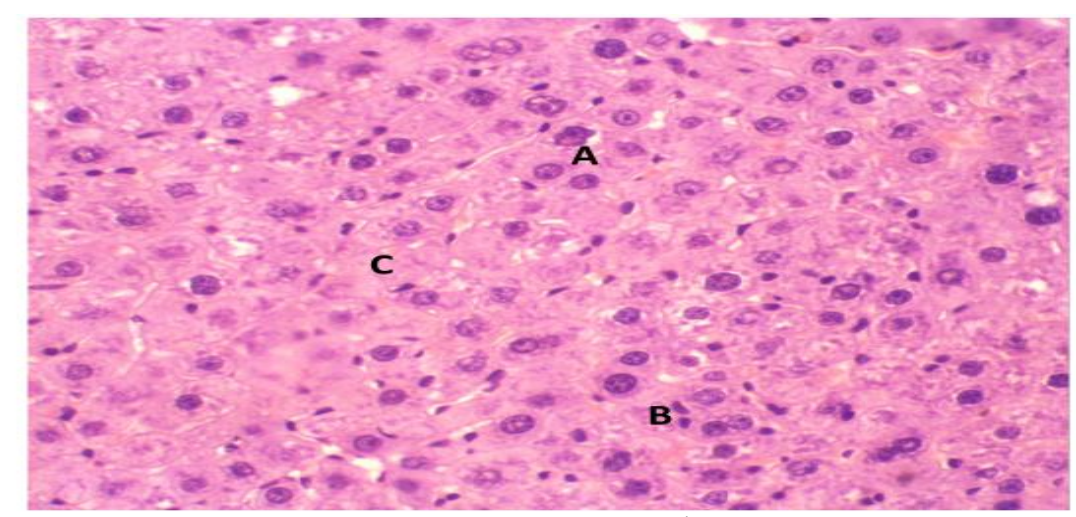

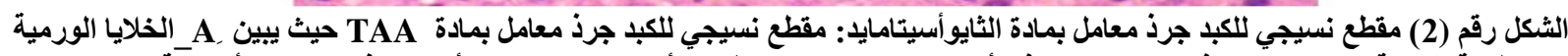

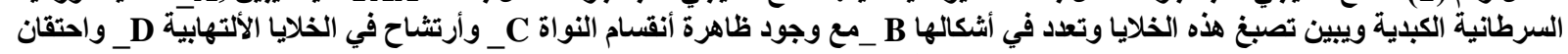

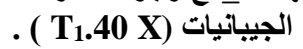




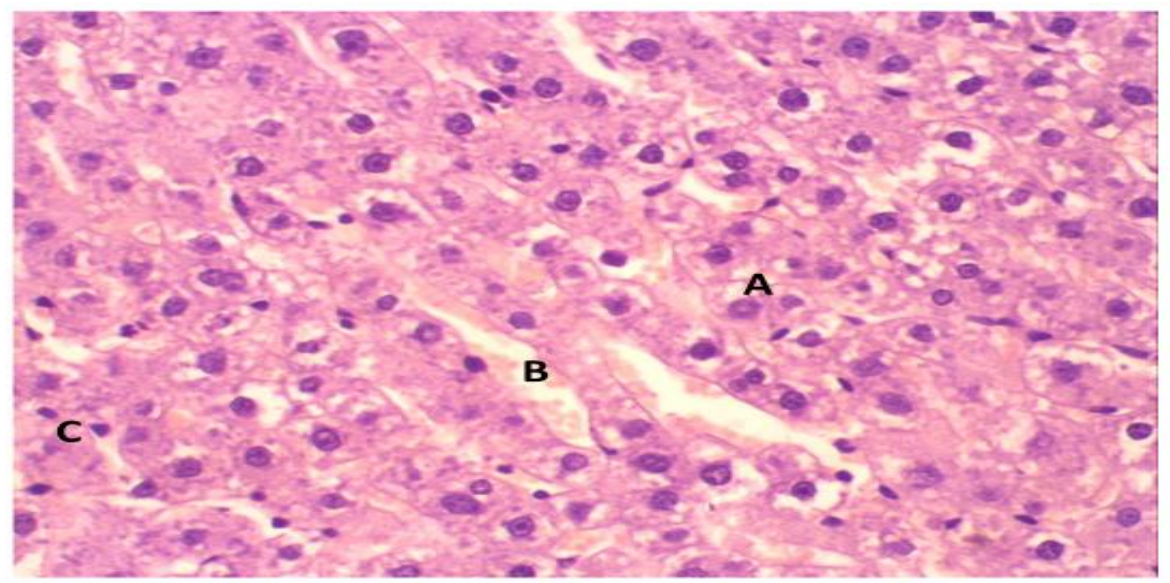

الثكل رقم (3) مقطع نسيجي للكبد جرذ معامل بمادة الثايوأسيتامايد والمستخلص النباتي اللب :مقطع نسيجي للكبد جرذ معامل بمادة TAA ومستخلص اللب حيث A_ يبين ظهور بعض الخلايا الورمية B _ وتكاثر خلايا كوفر C_C_انسداد الجيبانيات. (TM1.40X)

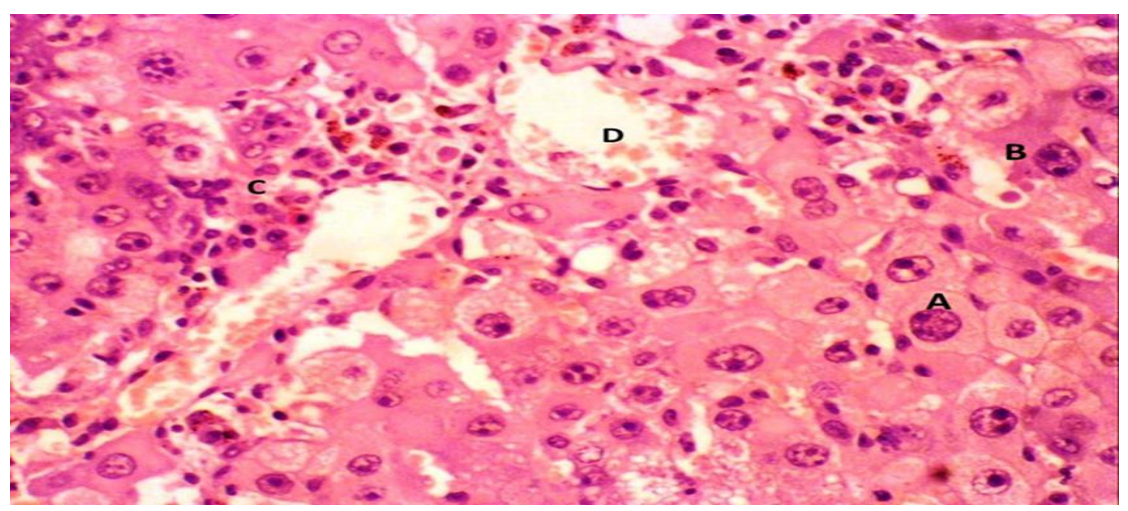

الثكل رقم (4) مقطع نسيجي للكبد جرذ معامل بمادة الثايوأسيتامايد والمستخلص النباتي البذور : مقطع نسيجي للكبد جرذ معامل بمادة TAA ومستخلص

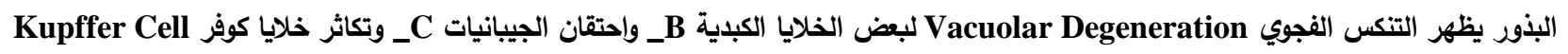
(T.M.40X)

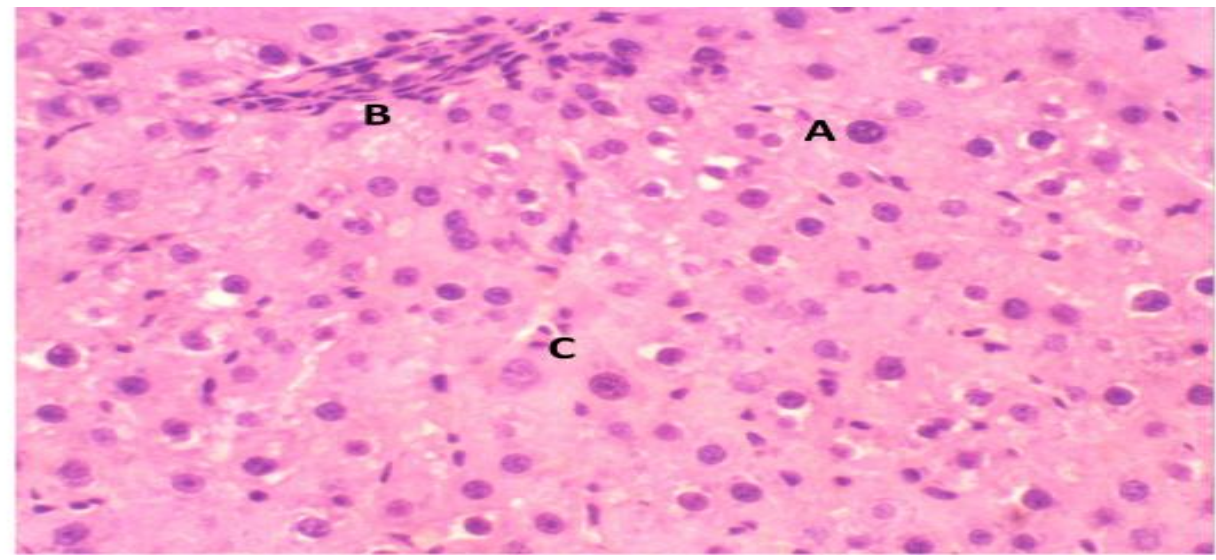

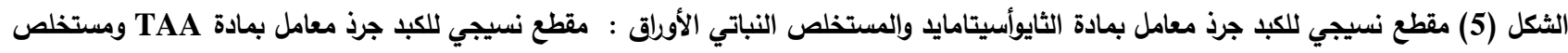

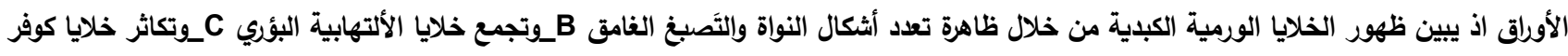
(TM.40X) 
: الأستنتاجات : (1)

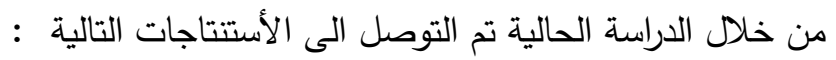
1 ــ وجود أرتفاع معنوي للجرذان المعاملة بمادة TAA لكل من المالونديالديهايد، الفوسفاتيز القلوي،البيلروبين الكلي، الأسبارتيت ترانس أمينيز، الألنين ترانس أمينيز ، والفا فيتو بروتين مقارنة بمجموعة جرذان السيطرة.

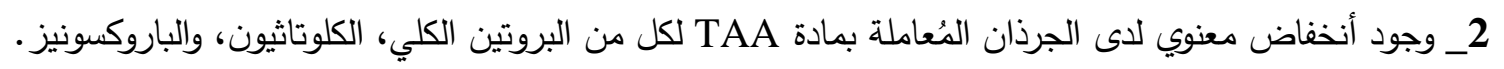

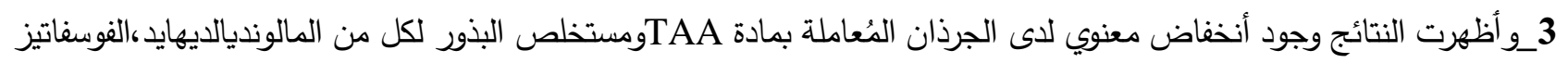

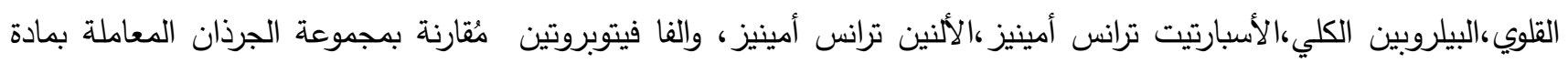
TAA ومستخلص اللب والأوراق.

4_ كما بينت النتائج بحصول أرتفاع معنوي لاى الجرذان المعاملة بمادة TAA ومستخلص البذور لكل من البروتين الكلي ، الكلوتاثيون ، والباروكسونيز مقارنة بمجموعة الجرذان المعاملة بمستخلص اللب، والأوراق.

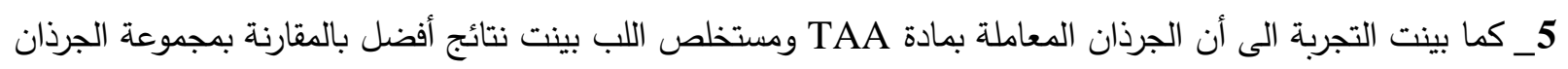
المعاملة بمادة TAA ومستخلص بئس الأوراق.

Acknowledgments: شكر وتقدير أتوجه بالثكر والتقدير لعمادة كلية التربية للعلوم الصرفة ورئاسة قسم الكيمياء والتدرسين في القسم على تثجيعهم ودعمهم المستمرين

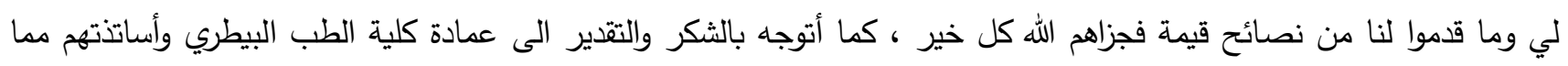

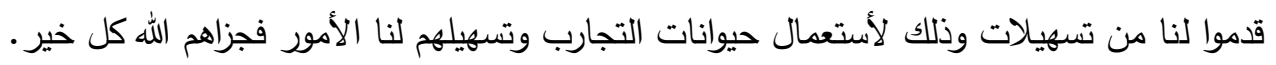

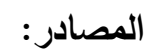

1. Watson, J., K. Hydon, and P. Lodge, Primary and secondary liver tumours. InnovAiT, 2016. 9(8): p. 477-482.

2. Lee, W.C. and M.F. Chen, Epidemiology, Etiology, and Natural History of Hepatocellular Carcinoma. Malignant Liver Tumors, 2009: p. 52-55.

3. Melato, M., et al., Relationship between cirrhosis, liver cancer, and hepatic metastases. An autopsy study. Cancer, 1989. 64(2): p. 455-459.

4. Okoro-Shekwaga, C. and Z.D. Osunde, Physical properties of soursop (Annona muricata) seeds. International Journal of Engineering Research \& Technology, 2013. 2(3): p. 1-5.

5. Tomás, M., et al., Effect of simvastatin therapy on paraoxonase activity and related lipoproteins in familial hypercholesterolemic patients. Arteriosclerosis, thrombosis, and vascular biology, 2000. 20(9): p. 2113-2119.

6. Agbai, E., et al., Effect of aqueous extract of Annona muricata seed on atherogenicity in streptozotocin-induced diabetic rats. African Journal of Pharmacy and Pharmacology, 2015. 9(30): p. 745-55.

7. Kuete, V., et al., Cytotoxicity of methanol extracts of Annona muricata, Passiflora edulis and nine other Cameroonian medicinal plants towards multi-factorial drug-resistant cancer cell lines. Springerplus, 2016. 5(1): p. 1666.

8. Tiwari, P., et al., Phytochemical screening and extraction: a review. Internationale pharmaceutica sciencia, 2011. 1(1): p. 98-106.

9. Gavamukulya, Y., et al., Phytochemical screening, anti-oxidant activity and in vitro anticancer potential of ethanolic and water leaves extracts of Annona muricata (Graviola). Asian Pacific journal of tropical medicine, 2014. 7: p. S355-S363.

10. Abdel-Hamid, N., M. El-Moselhy, and M. Fawzy, Novel Panel of Early Diagnostic Markers for Experimental Hepatocellular Carcinoma. Journal of Health Science, 2012. 2(2): p. 14-18. 
11. Akhtar, T. and N. Sheikh, An overview of thioacetamide-induced hepatotoxicity. Toxin Reviews, 2013. 32(3): p. 43-46.

12. Stillinger, D., K. Helland, and C. Van Atta, Experiments on the transition of homogeneous turbulence to internal waves in a stratified fluid. Journal of Fluid Mechanics, 1983. 131: p. 91122.

13. Kirkwood, B.R., Essentials ofMedical Statistics. Boston, Mass: Black-well Scientific Publications, 1988.

14. Ehrsson, Y.T., A. Langius-Eklöf, and G. Laurell, Nutritional surveillance and weight loss in head and neck cancer patients. Supportive Care in Cancer, 2012. 20(4): p. 757-765.

15. Ardiansa, B., A. Ariyanti, and A. Hapid, Pengaruh konsentrasi dan lama perendaman kayu sengon (Paraserianthes falcataria L. Nielsen) dalam ekstrak daun sirsak (Annona muricata L.) terhadap serangan rayap tanah (Coptotermes sp.). Jurnal Warta Rimba, 2014. 2(1).

16. Ezejindu, N., et al., The histological effect of ethanolic leaf extracts of Annona muricata (soursop) on liver of adult wistar rats. IJHSR, 2015. 5: p. 125-129.

17. Legaspi, A., et al., Whole body lipid and energy metabolism in the cancer patient. Metabolism, 1987. 36(10): p. 958-963.

18. Waterhouse, C., Oxidation and metabolic interconversion in malignant cachexia. Cancer Treat Rep, 1981. 65(Suppl 5): p. 61-6.

19. Beisel, W.R., Metabolic response to infection. Annual review of medicine, 1975. 26(1): p. 920.

20. Adewole, S. and J. Ojewole, Protective effects of Annona muricata Linn.(Annonaceae) leaf aqueous extract on serum lipid profiles and oxidative stress in hepatocytes of streptozotocintreated diabetic rats. African journal of traditional, complementary and alternative medicines, 2009. 6(1).

21. Wong, W.-L., et al., Hepatoprotective effects of Panus giganteus (Berk.) corner against thioacetamide-(TAA-) induced liver injury in rats. Evidence-Based Complementary and Alternative Medicine, 2012. 2012.

22. Ukwubile, C.A., Phytochemical screening and anti-ovarian cancer properties of Annona muricata Linn (Annonaceae) seed ethanol extract. Int J. Pharm. Front. Res, 2012. 2: p. 9-17.

23. de Castro, F.A., et al., Características físicas e químicas da graviola. Pesquisa Agropecuária Brasileira, 1984. 19(3): p. 361-365.

24. Gebicki, S. and J.M. Gebicki, Formation of peroxides in amino acids and proteins exposed to oxygen free radicals. Biochemical Journal, 1993. 289(3): p. 743-749.

25. Wang, L.-B., et al., Amino acid uptake in arterio-venous serum of normal and cancerous colon tissues. World journal of gastroenterology, 2004. 10(9): p. 1297.

26. Sawant, T.P. and R.S. Dongre, Bio-chemical compositional analysis of Annona muricata: a miracle fruit's review. International Journal of Universal Pharmacy and Bio Sciences, 2014. 3(2): p. 82-104.

27. Yeo, W., et al., Quality of life is predictive of survival in patients with unresectable hepatocellular carcinoma. Annals of Oncology, 2006. 17(7): p. 1083-1089.

28. Widyastuti, D.A. and P. Rahayu, Antioxidant capacity comparison of ethanolic extract of soursop (Annona muricata Linn.) leaves and seeds as cancer prevention candidate. Biology, Medicine, \& Natural Product Chemistry, 2017. 6(1): p. 1-4.

29. Schmilovitz-Weiss, H., et al., Quantitation of alpha-fetoprotein messenger RNA for early detection of recurrent hepatocellular carcinoma: A prospective pilot study. Cancer Detection and Prevention, 2006. 30(2): p. 204-209.

30. Ali, R.S., W. chassab Hmood, and M.A.-w. Alsirrag. Preparation of dried children food mixes from locally vegetable sources and estimation of their amino and fatty acids content. in IOP Conference Series: Materials Science and Engineering. 2019. IOP Publishing. 
31. Nourazarian, A.R., P. Kangari, and A. Salmaninejad, Roles of oxidative stress in the development and progression of breast cancer. Asian Pac J Cancer Prev, 2014. 15(12): p. 474551.

32. Saleem, U., et al., AJAB. Asian J Agri \& Biol, 2017. 5(1): p. 38-46.

33. Vijayameena, C., et al., Original Research Article Phytochemical screening and assessment of antibacterial activity for the bioactive compounds in Annona muricata. Int. J. Curr. Microbiol. Appl. Sci, 2013. 2: p. 1-8.

34. Demir, S., et al., Role of free radicals in peptic ulcer and gastritis. Turkish journal of Gastroenterology, 2003. 14(1): p. 39-43.

35. Aviram, M., Introduction to paraoxonases. Journal of lipids, 2012. 2012.

36. Ragasa, C.Y., et al., Acetogenins from Annona muricata. Pharmacognosy journal, 2012. 4(32): p. 32-37.

37. Bailey, T., P. Berg, and C. Sandy, The effect of high-performance work practices on employee earnings in the steel, apparel, and medical electronics and imaging industries. ILR Review, 2001. 54(2A): p. 525-543.

38. Kew, M.C., Serum aminotransferase concentration as evidence of hepatocellular damage. The Lancet, 2000. 355(9204): p. 591-592.

39. Idrus, R., N. Bialangi, and L. Alio, Isolation and characterization of alkaloid compound from soursop (Annona muricata Linn.) seeds. Chemistry Education Science Faculty. Universitas Negeri Gorontalo, 2012. 